\title{
Correlation between chemical composition, EHGE and TME of corn for ducks
}

\author{
Y.J. Chen ${ }^{1,2,3}$, Z.Y. Wang ${ }^{3}$, C.G. Du ${ }^{2,3}$, Z.L. Qi ${ }^{1 \#}$, Y.Q. Guo ${ }^{2}$, X.H. Shen ${ }^{2}$, Z.K. Guo ${ }^{2}$, \\ C. Zhang ${ }^{2}$, Y.F. Zhang ${ }^{1}$ \& H.M. Yang ${ }^{1}$ \\ ${ }^{1}$ College of Animal Science \& Technology, Huazhong Agricultural University, Wuhan 430070, China \\ ${ }^{2}$ Vocational and Technical College, Inner Mongolia Agricultural University, Baotou, Inner Mongolia 014109, China \\ ${ }^{3}$ College of Animal Science, Inner Mongolia Agricultural University, Hohhot, Inner Mongolia 010018, China
}

(Submitted 15 December 2018; Accepted 14 June 2019; Published 13 October 2020)

\author{
Copyright resides with the authors in terms of the Creative Commons Attribution 4.0 South African Licence. \\ See: http://creativecommons.org/licences/by/4.0/za \\ Condition of use: The user may copy, distribute, transmit and adapt work, but must recognise the authors and the South African \\ Journal of Animal Science.
}

\begin{abstract}
Correlations between chemical composition, enzymatic hydrolysate gross energy (EHGE), and true metabolizable energy (TME) of corn for ducks were investigated. Twenty-two corn samples were collected from various regions in 11 provinces of China. The crude protein (CP), ether extract (EE), neutral detergent fibre (NDF), Ash, gross energy (GE), dry matter (DM), amylopectin (AP), amylose (AM), total starch (TS), and AP/AM were determined for each sample. Five of the samples of corn were chosen at the mean, mean \pm 1 standard deviation (SD), and mean \pm 2 SD based on AP/AM. The EHGE of these samples was analysed using the pepsin-artificial small intestinal fluid enzymatic method. These five samples were also force-fed to male Cherry Valley ducks to assay their TME. Finally, correlation analyses were performed, and regression equations were established. Ash content, GE, and TS were highly related to EHGE. Univariate prediction equations were $\mathrm{EHGE}=11.8566 \mathrm{Ash}^{-0.0421}(P<0.05)$, EHGE $=0.1535 \mathrm{GE}^{1.5642}(P<0.05)$, and $\mathrm{EHGE}=$ $0.1020 \mathrm{TS}^{1.1561}(P<0.05)$. The total starch, AP/AM, and ash of the chemical compositions were highly related to TME. The corresponding univariate regression equations were TME $=21.9355 \mathrm{TS}^{-0.0910}(P<0.05)$, TME $=$ 15.6590AP/AM ${ }^{-0.0559}(P<0.05)$, and TME $=15.0778 \mathrm{Ash}^{0.0442}(P<0.05)$. The mean EHGE was equivalent to $78.5 \%$ of TME, but their correlation coefficient was low. In conclusion, chemical composition was predictive of EHGE and TME of corn samples for ducks, but the correlation of EHGE and TME was low.
\end{abstract}

Keywords: Cherry Valley duck, amylopectin, amylose, true metabolizable energy

"Corresponding author: zhiliqi@mail.hzau.edu.cn

\section{Introduction}

Duck production and breeding are important at present (Bond et al., 2008; Lin et al., 2014). Corn is the commonest grain feedstuff and is used widely in duck production. It is rich in starch, which is a direct and effective material to supply energy (Theurer et al., 1999). So, accurate determination of the energy utilization efficiency of corn was the main basis for deciding to establish a standard of nutritional requirements and to optimize feed formulation. Varieties of corn have different chemical compositions because of diverse sources and processing techniques. True metabolizable energy (TME) values differ in plant species (Dugger et al., 2007). So it is important to establish a database of types of corn. Knowledge of the ME of corn for ducks (Chinese Feedstuff Database, 2017) is limited. More ME values are needed of varieties of corn for ducks in China. Traditional biological methods contained feeding and metabolic tests to determine the energy of feedstuffs and the digestibility of nutrients. These methods were visual and scientific, but they were time consuming, expensive, and difficult to standardize. Thus, it was crucial improve the determination of TME.

Neutral detergent fibre (NDF) can be an effective indicator of the TME of wheat and wheat by-products for ducks (Wan et al., 2009; Mazhari et al., 2011). These results suggest strongly that the chemical composition of a feedstuff may be used to predict TME. Methods to determine chemical composition have been perfected by the Association of Official Analytical Chemists (AOAC, 2000). The enzymatic method is a dynamic digestion process, which adds exogenous enzymes to feedstuff, and is easy and rapid to implement. Digestibility of organic matter and energy content of hay predicted by the rumen fluid-neutral detergent method and the cellulose method had similar levels of accuracy (lantcheva et al., 1999). Thus, the 
enzymatic method can be used to predict energy value. However, there is little information about the correlation between chemical composition, EHGE and TME of corn for ducks from China.

Objectives of this study were to i) determine the chemical composition of 22 corn samples and select five representative corn samples based on the amylopectin to amylose ratio (AP/AM); ii) investigate the correlations between chemical composition, EHGE, and TME of these samples; and iii) establish relatively accurate prediction models to estimate TME.

\section{Materials and Methods}

Twenty-two corn samples were collected from different regions of China (Table 1). The amount of material in each sample was reduced by coning and quartering, and the remaining subsamples were ground through 40-mesh screen. Chemical composition of each ground sample (Table 2) was determined by methods from AOAC (2000) for dry matter (DM) (method 934.01), Ash (method 942.05), crude protein (CP) (method 955.04), and ether extract (EE) (method 920.39). Neutral detergent fibre was determined according to Van Soest et al. (1991) and gross energy (GE) was determined by adiabatic calorimetry (Parr Instruments Co., Moline, IL). Total starch, AM, and AP were determined using a modification of the Sene et al. (1997) method whereby corn was passed through a 100 mesh screen. Because the AP/AM ratio is an indicator of the structure of corn starch and affects starch digestion, it was used to choose five representative corn samples for further analysis.

Table 1 Sources of 22 samples used to assess nutritional value of corn for ducks

\begin{tabular}{lccccc}
\hline Sample & Source & Region & Sample & Source & Region \\
\hline 1 & Yantai in Shandong & East China & 12 & Yicheng in Hubei & Central China \\
2 & Haimen in Jiangsu & East China & 13 & Xuchang in Henan & Central China \\
3 & Hefei in Anhui & East China & 14 & Chengchow in Henan & Central China \\
4 & Wuhan in Hubei & Central China & 15 & Hohhot in Inner Mongolia & North China \\
5 & Xiantao in Hubei & Central China & 16 & Chifeng in Inner Mongolia & North China \\
6 & Hanchuan in Hubei & Central China & 17 & Chengde in Hebei & North China \\
7 & Xiangfan in Hubei & Central China & 18 & Shijiazhuang in Hebei & North China \\
8 & Honghu in Hubei & Central China & 19 & Shenyang in Liaoning & Northeast China \\
9 & Hannan in Hubei & Central China & 20 & Changchun in Jilin & Northeast China \\
10 & Yichang in Hubei & Central China & 21 & Qiqihar in Heilongjiang & Northeast China \\
11 & Xianning in Hubei & Central China & 22 & Urumqi in Sinkiang & Northwest China \\
& & & & & \\
\hline
\end{tabular}

Three $0.5 \mathrm{~g}$ samples of each of these corn samples were placed in $150 \mathrm{ml}$ conical flasks for in vitro digestion. A volume of $10 \mathrm{~mL}$ pepsin hydrochloric acid solution with concentration of $2 \mathrm{~g} / \mathrm{L}$ was added to each flask. The concentration of hydrochloric acid was calibrated with anhydrous sodium carbonate as 0.075 $\mathrm{mol} / \mathrm{L}$. Each flask was then incubated in a water bath at $38^{\circ} \mathrm{C}$ for three hours. The solution was neutralized with $0.75 \mathrm{~mL} 1 \mathrm{~mol} / \mathrm{L}$ sodium hydroxide solution, and $10 \mathrm{~mL}$ artificial small intestinal fluid was added to each flask. The $\mathrm{pH}$ in each flask was approximately 6.60. The artificial small intestinal fluid was composed of amylase, lipase, trypsin, and chymotrypsin. The flask was returned to the water bath and incubated at $38{ }^{\circ} \mathrm{C}$ for an additional 22 hours. The suspension was suction filtered, and the filter dried at $105^{\circ} \mathrm{C}$ and weighed. Gross energy and DM were determined for the residue (R). Following Zhao (2014), enzymatic dry matter digestibility (EDMD) and EHGE were calculated as follows:

$$
\begin{gathered}
\mathrm{EDMD}=\frac{100\left(\mathrm{FxDM}_{\mathrm{F}}-\mathrm{R}\right)}{\mathrm{FxDM}_{\mathrm{F}}} \\
\mathrm{EHGE}=\frac{100\left(\mathrm{FxDM}_{\mathrm{F}} \mathrm{XGE}_{\mathrm{F}}-\mathrm{RxGE}_{\mathrm{R}}\right)}{\mathrm{FxDM}_{\mathrm{F}}}
\end{gathered}
$$

where: $\mathrm{F}=$ weight of feedstuff; $\mathrm{DM}_{\mathrm{F}}=\mathrm{DM}$ of the feedstuff $(\%) ; \mathrm{R}=$ weight of dry residue after in vitro digestion; $\mathrm{GE}_{\mathrm{F}}=\mathrm{GE}$ of the feedstuff $(\mathrm{KJ} / \mathrm{g})$; and $\mathrm{GE}_{\mathrm{R}}=\mathrm{GE}$ of the residue after in vitro digestion $(\mathrm{KJ} / \mathrm{g})$. 
Table 2 Chemical composition of 22 corn samples from across China expressed on a dry matter basis

\begin{tabular}{|c|c|c|c|c|c|c|c|c|c|c|}
\hline Sample & AP, $\%$ & AM, \% & TS, \% & AP/AM & $\mathrm{CP}, \%$ & EE, \% & NDF, \% & Ash, \% & DM, \% & $\begin{array}{c}\mathrm{GE} \\
(\mathrm{MJ} / \mathrm{kg})\end{array}$ \\
\hline 1 & 27.10 & 14.31 & 66.79 & 1.89 & 6.88 & 3.14 & 11.47 & 2.18 & 86.52 & 15.50 \\
\hline 2 & 28.65 & 15.28 & 62.39 & 1.88 & 7.48 & 2.34 & 11.82 & 1.64 & 87.56 & 16.19 \\
\hline 3 & 28.44 & 12.55 & 60.24 & 2.27 & 8.00 & 2.80 & 11.02 & 1.36 & 85.49 & 16.16 \\
\hline 4 & 25.58 & 12.90 & 64.31 & 1.98 & 7.44 & 4.16 & 11.49 & 1.49 & 85.61 & 15.75 \\
\hline 5 & 26.74 & 14.37 & 58.68 & 1.86 & 6.76 & 3.07 & 12.31 & 2.09 & 85.64 & 15.76 \\
\hline 6 & 27.71 & 12.05 & 56.60 & 2.30 & 6.54 & 3.48 & 10.77 & 0.94 & 85.11 & 15.56 \\
\hline 7 & 31.23 & 11.76 & 61.73 & 2.66 & 6.69 & 3.80 & 11.02 & 1.04 & 85.36 & 16.64 \\
\hline 8 & 29.70 & 12.76 & 63.26 & 2.33 & 7.26 & 2.64 & 9.83 & 1.42 & 84.71 & 15.48 \\
\hline 9 & 19.61 & 10.37 & 56.02 & 1.89 & 8.03 & 5.29 & 11.19 & 0.91 & 85.27 & 16.33 \\
\hline 10 & 31.94 & 12.94 & 56.00 & 2.47 & 7.88 & 4.10 & 11.32 & 1.22 & 85.68 & 15.23 \\
\hline 11 & 27.23 & 10.45 & 57.43 & 2.60 & 8.30 & 4.83 & 12.08 & 1.22 & 87.00 & 16.58 \\
\hline 12 & 32.05 & 13.03 & 60.49 & 2.46 & 7.52 & 6.00 & 10.85 & 1.24 & 87.74 & 16.48 \\
\hline 13 & 30.42 & 14.30 & 62.75 & 2.13 & 7.32 & 3.23 & 10.42 & 1.01 & 86.45 & 15.66 \\
\hline 14 & 28.85 & 12.77 & 53.60 & 2.26 & 8.76 & 2.02 & 10.01 & 2.37 & 84.31 & 15.28 \\
\hline 15 & 23.41 & 14.15 & 66.67 & 1.65 & 5.81 & 4.33 & 12.33 & 0.81 & 87.66 & 16.69 \\
\hline 16 & 24.84 & 15.28 & 66.15 & 1.63 & 6.32 & 3.45 & 12.22 & 1.00 & 86.20 & 15.77 \\
\hline 17 & 27.45 & 14.19 & 61.62 & 1.93 & 8.23 & 4.94 & 12.41 & 1.11 & 88.21 & 16.40 \\
\hline 18 & 20.59 & 13.12 & 61.50 & 1.57 & 7.37 & 4.05 & 15.95 & 2.75 & 87.13 & 16.37 \\
\hline 19 & 27.00 & 14.05 & 63.69 & 1.92 & 8.40 & 3.68 & 10.27 & 1.06 & 84.69 & 15.25 \\
\hline 20 & 24.13 & 14.41 & 64.89 & 1.67 & 6.93 & 4.46 & 10.59 & 1.18 & 86.58 & 17.10 \\
\hline 21 & 20.75 & 14.39 & 61.22 & 1.44 & 6.78 & 3.66 & 14.25 & 1.11 & 86.74 & 16.29 \\
\hline 22 & 19.31 & 12.43 & 56.00 & 1.55 & 7.97 & 4.32 & 15.93 & 1.38 & 87.95 & 16.74 \\
\hline Mean & 26.49 & 13.27 & 61.00 & 2.02 & 7.39 & 3.81 & 11.80 & 1.39 & 86.26 & 16.05 \\
\hline SD & 3.77 & 1.32 & 3.72 & 0.35 & 0.74 & 0.95 & 1.63 & 0.50 & 1.12 & 0.54 \\
\hline
\end{tabular}

AP: amylopectin, AM: amylose, AP/AM: ratio of amylopectin to amylose; TS: total starch, CP: crude protein, EE: ether extract, NDF: neutral detergent fibre, GE: gross energy, DM: dry matter.

The protocol of the animal experiment was approved by the Animal Experimental Ethical Inspection of Laboratory Animal Centre, Huazhong Agriculture University (HZAUDU-2015-005). Forty-eight adult male Cherry Valley ducks were selected from Chunjiang duck factory (Huangpi, Hubei Province, China). The ducks were in good health and were similar in weight $(3.24 \pm 0.36 \mathrm{~kg})$. Prior to the experiment there was a seven-day wash-out period. The ducks were randomly assigned to six treatments of eight replicates of one duck each. Five groups of ducks were force-fed with one of the five corn samples, and the sixth group was fasted to determine the loss of endogenous energy. Ducks were caged individually throughout the experiment.

Force-feeding was carried out according to the modified bioassay of Sibbald (1976) and McNab and Blair (1988). Briefly, the complete formula diet (Wuhan Chia Tai Co., Ltd.) for adult meat ducks was removed on the first day of experiment. At eight and 32 hours after feed withdrawal, each duck was force-fed with a warm $38.5 \%(\mathrm{v} / \mathrm{v})$ glucose solution to reduce the stress of fasting. Then, at 36 hours after feed withdrawal, $60 \mathrm{~g}$ representative corn samples (Samples $6,11,15,19,21$ ) varying in the ratio of AP to AM were force-fed to the fasted ducks. Each duck had a clean tray inserted beneath its cage and the excreta were collected for 36 hours. Samples were deemed valid if the duck did not vomit and the excreta was not lost. There were at least six excreta samples for each tested feed sample. To determine the loss of endogenous energy, ducks were fasted for 72 hours, and excreta samples were collected for 36 hours. A volume of $10 \mathrm{ml}$ of $10 \%$ hydrochloric acid was added to the excreta of each duck during the collecting period. After drying at $65{ }^{\circ} \mathrm{C}$ and weighing, the excreta samples were ground through a 40-mesh screen and the GE and DM were determined. The apparent metabolizable energy (AME) and TME were calculated according to Wan (2009): 


$$
\begin{gathered}
T M E=[E I-(E O-E E L)] / F I \text { and } \\
A M E=(E I-E O) / F I
\end{gathered}
$$

where: $\mathrm{EI}=\mathrm{GE}$ of the intake of the feedstuff; $\mathrm{EO}=\mathrm{GE}$ voided of the feedstuff; $\mathrm{EEL}=$ loss of endogenous energy; and $\mathrm{FI}=$ intake of the feedstuff $(60 \mathrm{~g})$.

The SAS statistical analysis software (SAS Institute Inc., Cary, North Carolina, USA) was used for all data analyses.. Correlation analyses were performed using CORR program. The results were shown as mean \pm SD. Regression equations were established between chemical composition and EHGE, and chemical composition and TME. Enzymatic hydrolysate gross energy and TME were compared by T-test. The variance was considered significant when $P<0.05$.

\section{Results}

The EHGE and EDMD of the five representative samples are shown in Table 3. On a dry matter basis, the EHGE was from 9.50 to $16.77 \mathrm{MJ} / \mathrm{kg}$, and EDMD was between 58.73 and 90.12 . The TME of the corn samples is shown in Table 4. On air dry matter basis, TME varied from $13.68 \mathrm{MJ} / \mathrm{kg}$ to $15.91 \mathrm{MJ} / \mathrm{kg}$.

Table 3 Nutritional values of 5 representative corn samples determined by the enzymatic method (\% dry

\begin{tabular}{|c|c|c|c|c|c|c|c|}
\hline \multirow{2}{*}{ Nutritional values } & \multicolumn{5}{|c|}{ Sample } & \multirow{2}{*}{ Mean } & \multirow{2}{*}{ SD } \\
\hline & 21 & 15 & 19 & 6 & 11 & & \\
\hline GE (MJ/kg) & 18.78 & 19.04 & 18.01 & 18.28 & 19.06 & 18.63 & 0.42 \\
\hline DM , \% & 86.74 & 87.66 & 84.69 & 85.11 & 87.00 & 86.24 & 1.14 \\
\hline EDMD , \% & 90.12 & 72.91 & 70.47 & 69.92 & 58.73 & 72.43 & 10.11 \\
\hline EHGE $(\mathrm{MJ} / \mathrm{kg})$ & 16.77 & 12.44 & 10.44 & 10.09 & 9.50 & 11.85 & 2.65 \\
\hline
\end{tabular}
matter basis)

\begin{tabular}{|c|c|c|c|c|c|c|c|}
\hline \multirow{2}{*}{ Nutritional values } & \multicolumn{5}{|c|}{ Sample } & \multirow{2}{*}{ Mean } & \multirow{2}{*}{ SD } \\
\hline & 21 & 15 & 19 & 6 & 11 & & \\
\hline True metabolizable energy, MJ/kg & 15.91 & 15.50 & 13.68 & 14.66 & 15.70 & 15.09 & 0.82 \\
\hline Apparent metabolizable energy, MJ/kg & 14.13 & 13.87 & 12.04 & 13.02 & 13.89 & 13.21 & 0.68 \\
\hline Digestibility of dry matter, $\%$ & 86.03 & 81.85 & 77.63 & 83.89 & 83.09 & 81.62 & 2.16 \\
\hline
\end{tabular}

Table 4 True metabolizable energy of five representative corn samples (\% dry matter basis)

Correlations of chemical composition with EHGE and TME are shown in Table 5. Ash, GE, and TS were highly correlated with EHGE, so three regression equations were established as:

$E H G E=11.8566 A_{s h}^{-0.0421} ; E H G E=0.1535 G E^{1.5642} ;$ and $E H G E=0.1020 T S^{1.1561}($ all $P=0.01)$

Likewise, TS and AP/AM were highly, but negatively correlated to TME. Ash was highly positively correlated to TME. Thus, three additional regression equations were established as:

$$
T M E=11.8566 A s h^{0.0442} T M E=21.9355 T S^{-0.910} ; \text { and } T M E=0.6590\left(\frac{A P}{A M}\right)^{-0.0559} \quad(\text { all } P<0.001)
$$

The correlation coefficient between EHGE and TME was low at 0.3853. Values of EHGE and TME were compared by T-test and he EHGE values were less than the values of TME $(P=0.0436)$. The mean difference between TME and EHGE was 3.24 MJ/kg and thus EHGE approximately 78.5\% of TME. 
Table 5 Correlations of chemical components with enzymatic hydrolysate gross energy and total gross energy

\begin{tabular}{lcccc}
\hline \multirow{2}{*}{ Chemical component } & \multicolumn{2}{c}{ Enzymatic hydrolysate gross energy } & \multicolumn{2}{c}{ Total gross energy } \\
\cline { 2 - 5 } & Correlation & $P$-value & Correlation & $P$-value \\
\hline Amylopectin & -0.0076 & 0.9657 & -0.2777 & 0.6069 \\
Amylose & 0.2124 & 0.6738 & -0.7958 & 0.1611 \\
Total starch & 0.5821 & 0.3345 & -0.8714 & 0.1012 \\
Amylopectin:amylose ratio & -0.0657 & 0.8537 & -0.8185 & 0.1431 \\
Gross energy & 0.6181 & 0.3047 & 0.0350 & 0.9050 \\
Crude protein & -0.4534 & 0.4443 & -0.5180 & 0.9043 \\
Ether extract & 0.1927 & 0.6950 & 0.3940 & 0.4973 \\
Ash & -0.8853 & 0.0902 & 0.8087 & 0.1508 \\
Neutral detergent fibre & & & 0.0529 & 0.8736 \\
Dry matter & 0.5335 & 0.3754 & 0.0501 & 0.8782 \\
\hline
\end{tabular}

\section{Discussion}

The observed values for chemical composition of the corn samples showed that the mean content of DM, CP, EE, and ash approached previously published values (NRC, 1994; Zhang et al., 2018). Batal et al. (2012) reported that the chemical compositions of yellow corn were that DM was $86 \%$, CP was $7.5 \%$, EE was $3.5 \%$, crude fibre (CF) was $1.9 \%$, ash was $1.1 \%$, and ME for poultry was $14.17 \mathrm{MJ} / \mathrm{kg}$. Most of the chemical compositions of corn were consistent with these results, although CF was not consistent with NDF in this study, because the methods of determination of CF and NDF differ. Furthermore, the results of AME and TME approached the ME for poultry. This suggests that varieties of corn in China are similar to those grown internationally. In this study, the variations of EE, ash and AP/AM were greater than others' indicators of nutritional content because the cultivars and growing conditions were different (Sandhu et al., 2004). Zhou (2010) reported the AM, AP, and AP/AM of 21 corn samples as $19.82 \%, 60.09 \%$, and $3.04 \%$. The AM value approached that of this study, but the AP and AP/AM were higher than the present results.

The amylopectin to amylose ratio is not only an important index to reflect starch structure, but also a crucial factor in the digestion of starch. In the 22 samples of corn that were evaluated in this study, the ratio was reasonably $(P \leq 0.10)$ correlated with NDF $(-0.61)$, DM $(-0.37)$, and TS $(-0.35)$. Therefore, five samples were chosen for further study based on the AP/AM. As the content of AP increased and the content of AM decreased their AP/AM increased from 1.44 to 2.60 .

The in vitro experiment, which used enzymes to simulate the in vivo digestion process, developed quickly. A one-step enzymatic method and a two-stage method were proposed by some researchers (Denek \& Deniz, 2004a). The in vitro method was successful in predicting digestible energy and digestibility of DM, and organic matter (Fang et al., 2012). Previously, in vivo DM, organic matter digestibility, and ME of corn were found to be $83.81 \%, 83.90 \%$ and $13.52 \mathrm{MJ} / \mathrm{kg}$, respectively, with the corresponding in vitro values being $81.21 \%, 82.27 \%$, and $12.90 \mathrm{MJ} / \mathrm{kg}$ (Denek \& Deniz, 2004b). These authors concluded that the enzyme technique could be used instead of the in vivo method. In this study, the mean DM, EDMD, and EHGE of the five samples by the in vitro method were $86.24 \%, 72.43 \%$, and $11.85 \mathrm{MJ} / \mathrm{kg}$. The mean digestibility of dry matter (DDM) and TME by the in vivo method were $81.26 \%$ and $15.09 \mathrm{MJ} / \mathrm{kg}$. It is suggested that in vitro method might be used to determine in duck diet. However, ash, GE, and TS were highly related to EHGE allowing them to be used to predict EHGE effectively.

The AME of corn for ducks in the Chinese Feedstuff Database (2017) was $13.01 \mathrm{MJ} / \mathrm{kg}$, approaching the value of $13.21 \mathrm{MJ} / \mathrm{kg}$ found in this study. This suggests that these 22 corn samples are representative of corn in China. In this study, TS, AP/AM, and ash were chosen to predict TME, because these three characteristics of corn that could assessed chemically were closely related to TME. This was consistent with the results of Ren et al. (2012) and Jie et al. (2013). Ren et al. (2012) used of corn starch as a basal diet in determining the TME of protein feedstuffs for Chinese Yellow chickens. Likewise, Jie et al. (2013) used the chemical characteristics of corn distillers dried grains with solubles to predict their AME and TME contents for roosters. However, the present results were not completely consistent with those of Zhao (2008), who 
reported that NDF and GE could be used to predict TME. These authors used corn from different regions, but Zhao et al. (2008) used corn calibration samples. Perai et al. (2010) predicted the TME of meat and bone meal based on the CP, EE, and Ash content. Ahmadi et al. (2008) also used the group method based on these chemical compositions to predict the TME of feather meal and poultry offal meal. Their results were similar to the results of this study. The correlation coefficients between these chemical compositions and TME were high, but they were lower than TS and AP/AM, suggesting that the content of starch combined with other chemical composition could predict TME.

The correlation coefficient between EHGE and TME was low and the EHGE was significantly less than TME $(P<0.05)$. Zhao (2008) also reported that EHGE was lower than TME by $1.63-2.69 \mathrm{MJ} / \mathrm{kg}$, with a mean difference of $2.26 \mathrm{MJ} / \mathrm{kg}$. Differences in the samples of corn used in the two studies may explain the relatively minor differences between the present results and those that were used previously.

\section{Conclusions}

Chemical composition was predictive of EHGE and TME of corn samples for ducks. However, the correlation of values for EHGE and TME was low.

\section{Acknowledgments}

This work was supported by Chinese Key Research and Development Program (2016YFD0500507 and 2018YFD0501605), Fundamental Research Funds for the Central Universities (2662018Y079), Open Project of Wuhan Academy of Agricultural Sciences (Kfxkt201805), National Natural Science Foundation of China (31660701), Higher Educational Scientific Research Projects of Inner Mongolia Autonomous Region (NJZY18065), and Science and Technology Innovation Projects of Vocational and Technical College of Inner Mongolia Agricultural University (2017CXTD02). The authors thank Dr. Mark Goettel, formerly of Lethbridge Research Centre of Agriculture \& Agri-Food, Canada, for revising the manuscript.

\section{Authors' Contributions}

YJC, ZYW, and CGD contributed equally to this work, performing the experiments and writing the paper. ZLQ conceived and designed the experiments. YQG, XHS, ZKG, CZ, YFZ, and HMY participated in some aspects of the work, including conducting the experiments and analysing the data. They also reviewed the content of this article and suggested revisions.

\section{Conflict of Interest Declaration}

The authors have declared that no competing interests exist.

\section{References}

Ahmadi, H., Golian, A., Mottaghitalab, M. \& Nariman-Zadeh, N., 2008. Prediction model for true metabolizable energy of feather meal and poultry offal meal using group method of data handling-type neural network. Poult. Sci. 87, 1909-1912.

AOAC, 2000. Official Methods of Analysis of AOAC International, 17th edition. Association of Official Analytical Chemists, Arlington, VA, USA.

Batal, A., Dale N. \& Persia M., 2012. Ingredient analysis table. Feedstuffs. 83(38),16-17.

Bond, J.C., Esler, D. \& Williams, T.D., 2008. Breeding propensity of female harlequin ducks. J. Wildlife Manage. 72 (6), 1388-1393.

Chinese Feedstuff Database, 2017. Tables of feed composition and nutritive values in China. 28th edition. http://www.chinafeeddata.org.cn/picture/pdf/CFICout2017_1.pdf

Denek, N. \& Deniz, S., 2004a. The determination of digestibility and metabolizable energy levels of some forages commonly used in ruminant nutrition by in vitro methods. Turk. J. Vet. Anim. Sci. 28, 115-122.

Denek, N. \& Deniz, S., 2004b. The determination of energy levels in some cereal grains used in ruminant diets by in vivo and in vitro methods. Turk. J. Vet. Anim. Sci. 28(1), 185-193.

Dugger, B.D., Moore, M.L., Finger, R.S. \& Petrie, M.J., 2007. True metabolizable energy for seeds of common moist-soil plant species. J. Wildlife. Manage. 71, 1964-1967.

Fang, L.Y., Mao, T.T., Xie, L.N. \& Jiang, L.S., 2012. The additivity of digestible energy values and digestibility of dry matter, organic matter determined by in vitro method for growing pigs. J. Anim. Vet. Adv. 11, 2043-2047.

lantcheva, N., Steingass, H., Todorov, N. \& Pavlov, D., 1999. A comparison of in vitro rumen fluid and enzymatic methods to predict digestibility and energy value of grass and alfalfa hay. Anim. Feed. Sci. Tech. 81, 333-344.

Jie, Y.Z., Zhang, J.Y., Zhao, L.H., Ma, Q.G. \& Cheng, J., 2013. The correlation between the metabolizable energy content, chemical composition and color score in different sources of corn DDGS. J. Anim. Sci. Biotechnol. 4, 38.

Lin, R.L., Chen, H.P., Rouvier, R. \& Poivey, J.P., 2014. Selection and crossbreeding in relation to plumage color inheritance in three Chinese egg type duck breeds (Anas Platyrhynchos). Asian-Aust. J. Anim. Sci. 27, 10691074.

Mazhari, M., Golian, A. \& Kermanshahi, H., 2011. Effect of chemical composition and dietary enzyme supplementation on metabolisable energy of wheat screenings. Asian-Aust. J. Anim. Sci. 24, 386-393.

McNab, J.M. \& Blair, J.C., 1988. Modified assay for true and apparent metabolizable energy based on tube feeding. Br. Poult. Sci. 29, 697-707. 
NRC, 1994. Nutrient requirements of poultry. 9th rev. edition. National Academic Press, Washington, DC.

Perai, A.H., Moghaddam, H.N., Asadpour, S., Bahrampour, J. \& Mansoori, G., 2010. A comparison of artificial neural networks with other statistical approaches for the prediction of true metabolizable energy of meat and bone meal. Poult. Sci. 89, 1562-1568.

Ren, L.Q., Tan, H.Z., Zhao, F., Zhao, J.T., Zhang, J.Z. \& Zhang, H.F. 2012. Using corn starch as basal diet to determine the true metabolizable energy of protein feedstuffs in Chinese Yellow chickens. Poult. Sci. 91, 1394-1399.

Sandhu, K.S., Singh, N. \& Kaur, M., 2004. Characteristics of the different corn types and their grain fractions: physicochemical, thermal, morphological, and rheological properties of starches. J. Food. Eng. 64, 119-127.

Sene, M., Thevenot, C. \& Prioul, J.L., 1997. Simultaneous spectrophotometric determination of amylose and amylopectin in starch from maize kernel by multi-wavelength analysis. J. Cereal. Sci. 26, 211-221.

Sibbald, I.R., 1976. A bioassay for true metabolizable energy in feeding stuffs. Poult. Sci. 55, 303-308.

Theurer, C.B., Huber, J.T., Delgado-Elorduy, A. \& Wanderley, R., 1999. Invited review: Summary of steamflaking corn or sorghum grain for lactating dairy cows. J. Dairy. Sci. 82, 1950-1959.

Van Soest, P.J., Robertson, J.B. \& Lewis, B.A., 1991. Methods for dietary fiber, neutral detergent fiber, and non starch polysaccharides in relation to animal nutrition. J. Dairy. Sci. 74, 3583-3597.

Wan, H.F., Chen, W., Qi, Z.L., Peng, P. \& Peng, J., 2009. Prediction of true metabolizable energy from chemical composition of wheat milling by-products for ducks. Poult. Sci. 88, 92-97.

Zhang, L., Zhao, F., Zhang, H., Bian, G.Z., Wang, Y.M., Yang, X. \& Li, H. 2018. Validation of in vitro digestion using simulated small intestinal fluid with specific digestive activity to predict the metabolizable energy of feed ingredients for duck. Poult. Sci. 98(3), 1280-1287.

Zhao, C., Ding, W. Chen, F., Cheng, C. \& Shao, Q., 2014. Effects of compositional changes of AFEX-treated and HAFEX-treated corn stover on enzymatic digestibility. Bioresource Tech. 155, 34-40.

Zhao, F., Zhang, H.F., Hou, S.S. \& Zhang, Z.Y., 2008. Predicting metabolizable energy of normal corn from its chemical composition in adult Pekin ducks. Poult. Sci. 87(8), 1603-1608.

Zhou, Z., Wan, H.F., Li, Y., Chen, W., Qi, Z.L., Peng, P. \& Peng, J., 2001. The influence of the amylopectin/amylose ratio in samples of corn on the true metabolizable energy value for ducks. Anim. Feed Sci. Tech. 157(1-2), 99-103. 